\title{
SEED PROPAGATION OF RATH HADUN (Pterocarpus santalinus Linn.) AS EFFECTD BY METHOD OF SOAKING AND SCARIFICATION
}

\author{
H K M S Kumarasinghe, S Subasinghe S and K KI U Aruna Kumara \\ Faculty of Agriculture, University of Ruhuna
}

\begin{abstract}
Red Sandalwood (Pterocarpus santalinus Linn.) is an evergreen tree species grown under semi dry climates in well drained lateric soils. The reddish and fragrant heartwood has a range of medicinal, pharmaceutical, industrial and timber and economically placed in the same category as tusk and amber. The Red heartwood contains a range of constituents including santalin (Santalic Acid), Santaol, Pterocarpin, Homo-Petrocarpin and reported to have anticoagulant, anti inflammatory, anti expectorant, anti pyretic, anti bacterial and anti tumor properties. Expensive natural fabric paint produced from the powdered Red heartwood is used in wood carving of prestigious nature. The natural habitat of Red Sandalwood is India which is extensively exploited to the point of near extinction, thus placing it in the red list of endangered species under IUCN guidelines.
\end{abstract}

There is only a limited number of Red sandalwood trees in Sri Lanka, which were brought from India. Therefore, conservation and multiplication of Red sandal wood is of timely importance. Even though a single tree of Red Sandalwood produces several thousands of seeds, there is no single seedling under the tree. The local requirement of Red Sanders is met partly by Indian suppliers while substitutes with similar medicinal properties (Rath Kehiriya) are also being used.

Two separate pot experiments(Complete Randomized Design with three replicates) were conducted to study the seed germination as affected by method of soaking and scarification. Fully matured brown coloured fresh seeds were used for the experiments and viability of the seeds used for the experiment was 70 to $72 \%$. Three different soaking methods (i.e. 24 hours dipping in normal water, 24 hour soaking in running watc: alternatively soaked in running water for 12 hrs. followed by 12 hours of drying for 14 days ) and again differentiated with scarification and without scarification were used as treatments. Total germination percentage was counted up to 14 days.

Results revealed that Seed germination was significantly higher $(P>0.05)$ in scarified seeds $(48.8 \%)$ when compared to those without scarification $(6.1 \%)$. With regards to the soaking method, highest germination percentage $(31 \%)$ was observed in the treatment, $12 \mathrm{hrs}$ of alternate soaking and drying in running water for 14 days, which was not significantly different from the treatment that seeds were soaked in running water for 24 hrs. Therefore it can be concluded that germination of Red Sandalwood seeds could be substantially enhanced by scarification of the seed coat and seeds soaked in running water for $24 \mathrm{hrs}$. as well as $12 \mathrm{hrs}$ of alternate soaking and drying for 14 days.

Proceedings of the Ninth Annual Forestry and Environment Symposium 2003 of the Department of Forestry and Emvironmental Science, University of Sri Jayewardenepura, Sri Lanka 